\title{
O emprego de técnicas estatísticas para a compartimentação geoambiental da Serra de Martins-RN
}

\author{
Using statistical techniques to conduct the geo-environmental \\ compartmentalization of Serra de Martins-RN, Brazil
}

\author{
Jacimária Fonseca de Medeiros ${ }^{1}$ \\ Luiz Antonio Cestaro ${ }^{2}$ (D)
}

\section{Palavras-chave}

Análise sistêmica

Serra de Martins

Análise Multivariada

Análise de Agrupamentos

\begin{abstract}
Resumo
A abordagem sistêmica tem sido amplamente disseminada, com significativa aceitação e aplicabilidade na ciência geográfica, principalmente na Geografia Física. A abordagem geossistêmica se refere, muitas vezes apenas ao simples agrupamento de informações temáticas sobre os elementos naturais, empregando a sobreposição de mapas e a interpretação visual como as principais técnicas para individualização e espacialização das unidades homogêneas. Nesse sentido, esse artigo objetiva apresentar a compartimentação geoambiental da Serra de Martins-RN, realizada com suporte na abordagem sistêmica e utilizando a análise multivariada de agrupamento (cluster analysis) como técnica de identificação e de espacialização das unidades geoambientais. Os procedimentos metodológicos utilizados seguiram a ordem: tratamento e análise dos dados, taxonomia das unidades, descrições físico-geográficas, tabulação, e cartografia. Para a aplicação das técnicas estatísticas foi utilizado um conjunto de dados envolvendo variáveis geológicas, geomorfológicas, pedológicas, fitogeográficas e de cobertura da terra, das quais foram selecionadas as mais significativas aplicando-se a técnica de Análise de Componentes Principais a partir da variância mínima. O método possibilitou identificar e espacializar seis Classes de Fácies. Ao final, constatou-se que, embora exista conhecimento mais aprofundado em manipulação de dados e no uso de técnicas complexas, a aplicação de tratamento estatístico mostrou-se objetiva e eficaz para a compartimentação geoambiental.
\end{abstract}

Keywords:

Systemic analysis

Serra de Martins

Multivariate analysis

Analysis of Clusters

\begin{abstract}
The systemic approach has been widely disseminated, with significant acceptance and applicability in geographic science, especially in Physical Geography. The geosystemic approach often refers only to the simple grouping of thematic information on the natural elements, using map overlay and visual interpretation as the main techniques for individualization and spatialization of homogeneous units. Thus, this article aims to present the geoenvironmental compartmentalization of Serra de Martins-RN, performed with support in the systemic approach and using multivariate cluster analysis as a technique for identification
\end{abstract}

\footnotetext{
1 Universidade do Estado do Rio Grande do Norte, UERN, Pau dos Ferros, RN, Brasil. jacimariamedeiros@uern.br
}

${ }^{2}$ Universidade Federal do Rio Grande do Norte, UFRN, Natal, RN, Brasil. lacestaro@gmail.com 
and spatialisation of geoenvironmental units. The methodological procedures used were: data treatment and analysis, unit taxonomy, physical-geographical descriptions, tabulation, and cartography. For the application of statistical techniques, a set of data was used involving geological, geomorphological, pedological, phytogeographical and land cover variables, from which the most significant ones were selected applying the Principal Component Analysis technique from the minimum variance. The method allowed to identify and to spatialize six Classes of Facies. In the end, it was verified that, although it requires a more in depth knowledge in data manipulation and in the use of complex techniques, the application of statistical treatment was objective and effective for the geoenvironmental compartmentalization.

\section{INTRODUÇÃO}

Sistemas ambientais são definidos como entidades bem organizadas onde a espacialidade é uma característica inerente (CHRISTOFOLETTI, 1999). A organização vislumbrada é uma síntese da estrutura e do funcionamento apresentados pelos elementos constituintes, em um processo evolutivo. Tendo em vista a grande diversidade de elementos constituintes, bem como os fluxos interativos entre eles, os sistemas ambientais são considerados como sistemas espaciais complexos.

Christofoletti (1980) salienta que os sistemas podem ser classificados em virtude das relações evidenciadas com o ambiente circundante, podendo ser isolados ou não isolados. Os sistemas isolados seriam aqueles que não sofrem perda ou recebimento de energia e/ou matérias do ambiente; já os sistemas não isolados, contrariamente, referem-se àqueles que mantêm relações com os demais sistemas do conjunto maior. O autor supracitado propõe ainda que os sistemas isolados podem ser fechados (com troca apenas de energia) ou abertos (com constantes trocas de matéria e energia). Diversas são as metodologias empregadas no estudo dos sistemas ambientais, cujo objetivo maior é entender sua complexidade, seus elementos constituintes e suas interações, considerando em instância maior a sustentabilidade ambiental para as sociedades (ISACHENKO, 1973; SOTCHAVA, 1977; CHRISTOFOLETTI, 1999; PHILIPPS, 1999; RODRIGUES et al., 2010; RODRIGUES; SILVA, 2016).

Santos (2004) destaca o Zoneamento como a compartimentação de uma região em porções territoriais, obtida pela avaliação dos atributos mais relevantes e de sua dinâmica. Por sua vez, o Zoneamento Geoambiental (ZGA), que identifica e espacializa unidades geoambientais, é uma forma de análise integrativa, que considera a compartimentação de um sistema a partir da interação dinâmica de elementos físicos e antrópicos. Essa abordagem sistêmica, como instrumento de gestão, é preconizada no Brasil a partir de diversos dispositivos, sejam legais (BRASIL, 2002; 2004), sejam de instrumentalização (BRASIL, 2006).

Esforços têm sido realizados na identificação e na compartimentação de espaços brasileiros ambientalmente homogêneos, seja em escalas pequena ou média seja em escala grande.

O Instituto Brasileiro de Geografia e Estatística (1997) aparece na literatura como um dos pioneiros em pesquisas envolvendo Zoneamento Geoambiental, especificamente no estado do Maranhão. Como critério, partiu-se de uma compartimentação morfoestrutural relacionada a litoestruturas e as feições do relevo e da rede de drenagem, resultando na identificação de 28 sistemas naturais.

No estado do Piauí, Barros e Castro (2006) realizaram um Zoneamento geoambiental na região de Campo Maior, uma área de tensão ecológica, utilizando o método geopedomorfológico, o qual permitiu a estratificação e identificação das características ecogeográficas (rocha-mãe, solo, relevo, vegetação) e os respectivos problemas geoambientais, embasados em Tricart e Keewitdejonge (1992).

Souza et al. (2009) realizaram a compartimentação geoambiental do estado do Ceará, aportada no elemento relevo, resultando em 13 unidades geoambientais. Também no estado do Ceará, Lima et al. (2010) desenvolveram uma proposta de ZGA para o munícipio do Crato, resultando na integração do mapa geológico, de unidades geomorfológicas, de solos e da rede de drenagem utilizando-se prioritariamente da estrutura geológica e geomorfológica como base para individualização dos sistemas e subsistemas Geoambientais. Também no Ceará, Carvalho e Meireles (2008) propõem o Zoneamento do litoral Leste de Fortaleza, seguindo metodologia baseada na 
análise ambiental e fundamentada na Teoria dos Geossistemas e na Ecodinâmica.

Nessa mesma ótica, Rossete e Santos (2012), realizaram um Zoneamento Ambiental no município de Querência, no Mato Grosso, apoiado no mapeamento das variáveis ambientais (planialtimetria, geologia, geomorfologia, pedologia, aptidão agrícola, vegetação e desmatamento).

Sato e Cunha (2013), buscou analisar de forma integrada o município de Itanhaém (São Paulo), tendo a abordagem sistêmica como a base teórica da pesquisa, fundamentou-se na metodologia de análise integrada da paisagem proposta por Rodrigues et al. (2010), concluindo que o município apresenta dois setores com características naturais distintas: o setor serrano, formado pelo planalto atlântico, pelas escarpas da serra do mar e pelos morros isolados; e o setor de planície, formado pela planície sedimentar.

Cavalcanti (2017) apresenta os geossistemas de Curuçá, Bahia, definindo os limites dos grupos de fácies, pelos tipos de modelados e por variações na vegetação/cobertura da terra. $\mathrm{O}$ autor identificou 29 diferentes grupos de fácies, representando os principais conjuntos ambientais do município em questão.

A partir de um sistema de classificação para as unidades naturais do estado do Rio Grande do Norte, com objetivo de um ZGA, Cestaro et al. (2007), definiram 9 regiões naturais, 17 geossistemas e 35 geofácies. Estas foram definidas a partir de mapeamentos das variáveis: geologia, geomorfologia, pedologia, altimetria, clima e vegetação. Nessa proposta de Zoneamento, a área correspondente à Serra de Martins abriga as seguintes regiões naturais: Depressão Sertaneja, Planalto Residual, Chapada e Planície Flúvio-Lacustre.

Com base no exposto, percebe-se que diversas são as técnicas utilizadas para identificar e delimitar os sistemas ambientais, com destaque para as técnicas totalizadoras, de sobreposição de mapas, de agrupamento multivariado, de processamento de imagens digitais e as técnicas que utilizam fatores controladores (BAILEY, 2009).

Sales (2004) estabelece uma crítica quanto a esse aspecto, elucidando que, no Brasil, a maioria das pesquisas que se utilizam da abordagem geossistêmica referem-se apenas a simples agrupamentos de informações temáticas sobre os elementos naturais, o que consequentemente gera complicação terminológica. Cavalcanti (2013) destaca que a
Teoria dos Geossistemas não se baseia puramente em um critério para análise da natureza, mas busca compreender as relações entre os diversos elementos e processos naturais. Tal fato elucida a necessidade de considerar a essência da metodologia sistêmica, concebida a partir do conjunto de relações que se estabelecem entre os elementos físicos, bióticos e antrópicos.

Poucos são os trabalhos, no Brasil, que utilizam as técnicas estatísticas, com destaque para Silva e Santos (2004). A complexidade do emprego de técnicas quantitativas, que exigem amostragem elaborada e intensa, muitas vezes onerosa, e conhecimento aprofundado dos tratamentos estatísticos dos dados e da análise dos resultados, provavelmente, seja um entrave na sua utilização mais frequente. Seu emprego, entretanto, reduz consideravelmente a subjetividade no processo de identificação das unidades e permite reconhecer mais detalhadamente as características individuais, os fatores ambientais que controlam e/ou exercem maior influência, e a hierarquização das unidades.

Entendendo, portanto, que os sistemas ambientais são unidades de organização homogênea, compostas por diversos elementos, com mútuas relações e continuamente submetidos aos fluxos de matéria e de energia, esse artigo objetiva apresentar a compartimentação geoambiental da Serra de Martins, no Rio Grande do Norte, apoiada na abordagem sistêmica e utilizando a análise multivariada a partir da técnica de agrupamento.

\section{PROCEDIMENTOS METODOLÓGICOS}

\section{Localização geográfica da área de estudo}

A Serra de Martins está localizada na Mesorregião Oeste do estado do Rio Grande do Norte, mais especificamente na Microrregião de Umarizal, e apresenta altitudes que se elevam desde os $210 \mathrm{~m}$ até $720 \mathrm{~m}$ acima do nível do mar. A área de estudo compreende parte dos municípios de Martins, Serrinha dos Pintos, Umarizal, Frutuoso Gomes e Antônio Martins, perfazendo aproximadamente $310 \mathrm{~km}^{2}$ (Mapa 1).

\section{Aquisição dos dados}

Foram sorteadas aleatoriamente, na área de estudo, as coordenadas centrais de 105 parcelas quadradas de $10 \mathrm{~m}$ x $10 \mathrm{~m}$ (Mapa 2). 
Mapa 1. Limites da área de estudo (linha vermelha), Serra de Martins-RN.

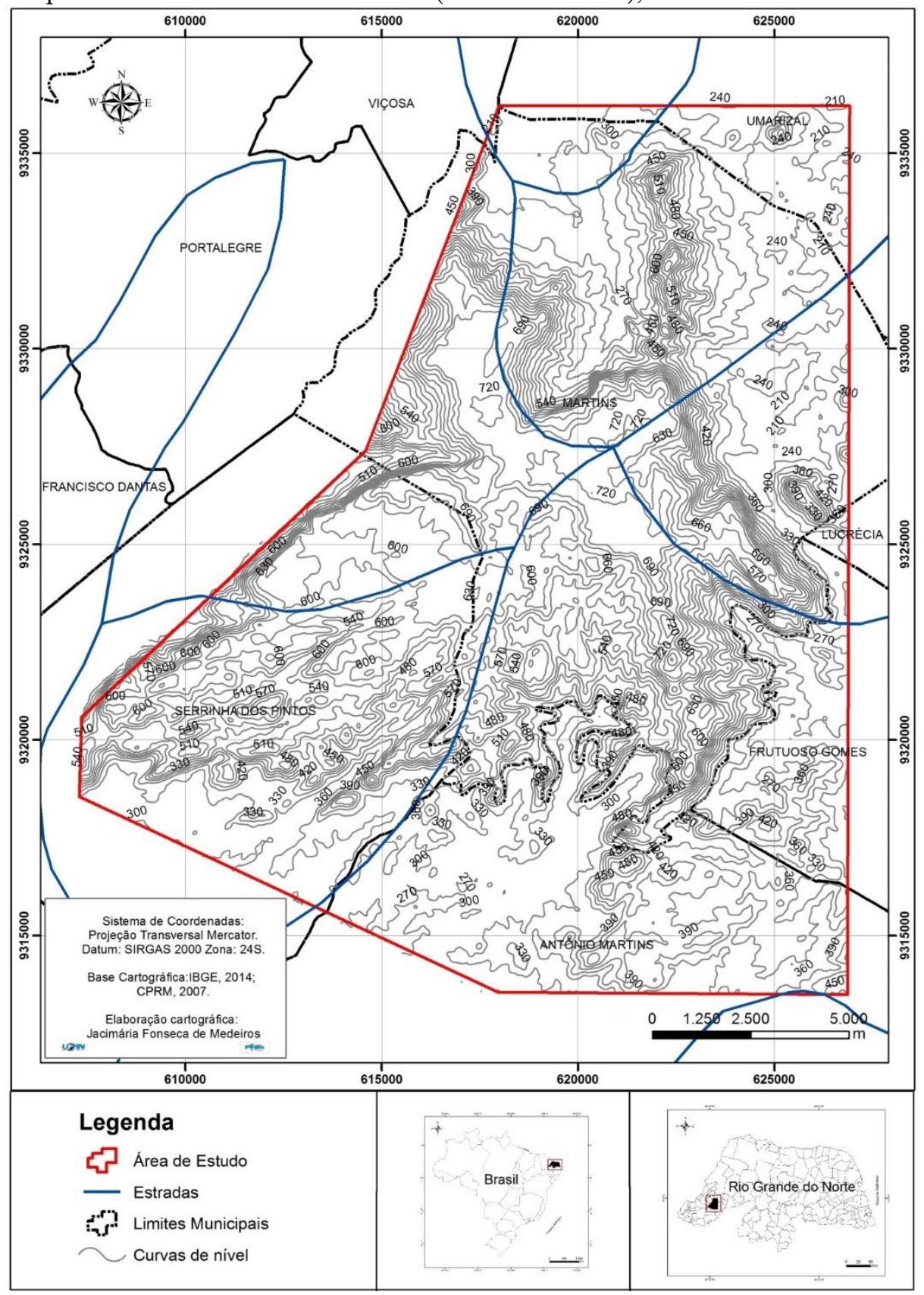

Fonte: elaboração cartográfica de Jacimária F. de Medeiros, jun., 2016.

Em cada parcela foi realizado o levantamento de dados ambientais, envolvendo a identificação de diferentes características da litologia, das formas de relevo, dos solos e da cobertura da terra, que constituíram as variáveis da pesquisa.

As variáveis geológicas enfatizaram o tipo de rochas, a partir de coleta de fragmentos tanto do embasamento, para o caso de afloramentos, como daquelas provenientes dos movimentos de massa, o colúvio. A posterior identificação da litologia foi realizada no Laboratório do Departamento de Geologia, Universidade
Federal do Rio Grande do Norte (UFRN).

As variáveis relacionadas à geomorfologia estão de acordo com IBGE (2009) e focam a posição do relevo (topo, encosta superior, meia encosta, encosta inferior, base e canal), curvatura (retilíneo, convexo e côncavo), e hipsometria (menor que 450 metros, entre 451 a 690 metros e acima de 690 metros). A declividade foi determinada de acordo com as seguintes classes: plano: $0^{\circ}$ a $3^{\circ}$, suave: $3^{\circ}$ a $8^{\circ}$, inclinado: $8^{\circ}$ a $20^{\circ}$, íngreme: $20^{\circ}$ a $45^{\circ}$, muito íngreme: $45^{\circ}$ a $75^{\circ}$, e escarpado: $>75^{\circ}$. 
Mapa 2. Localização dos pontos de controle na área de estudo.

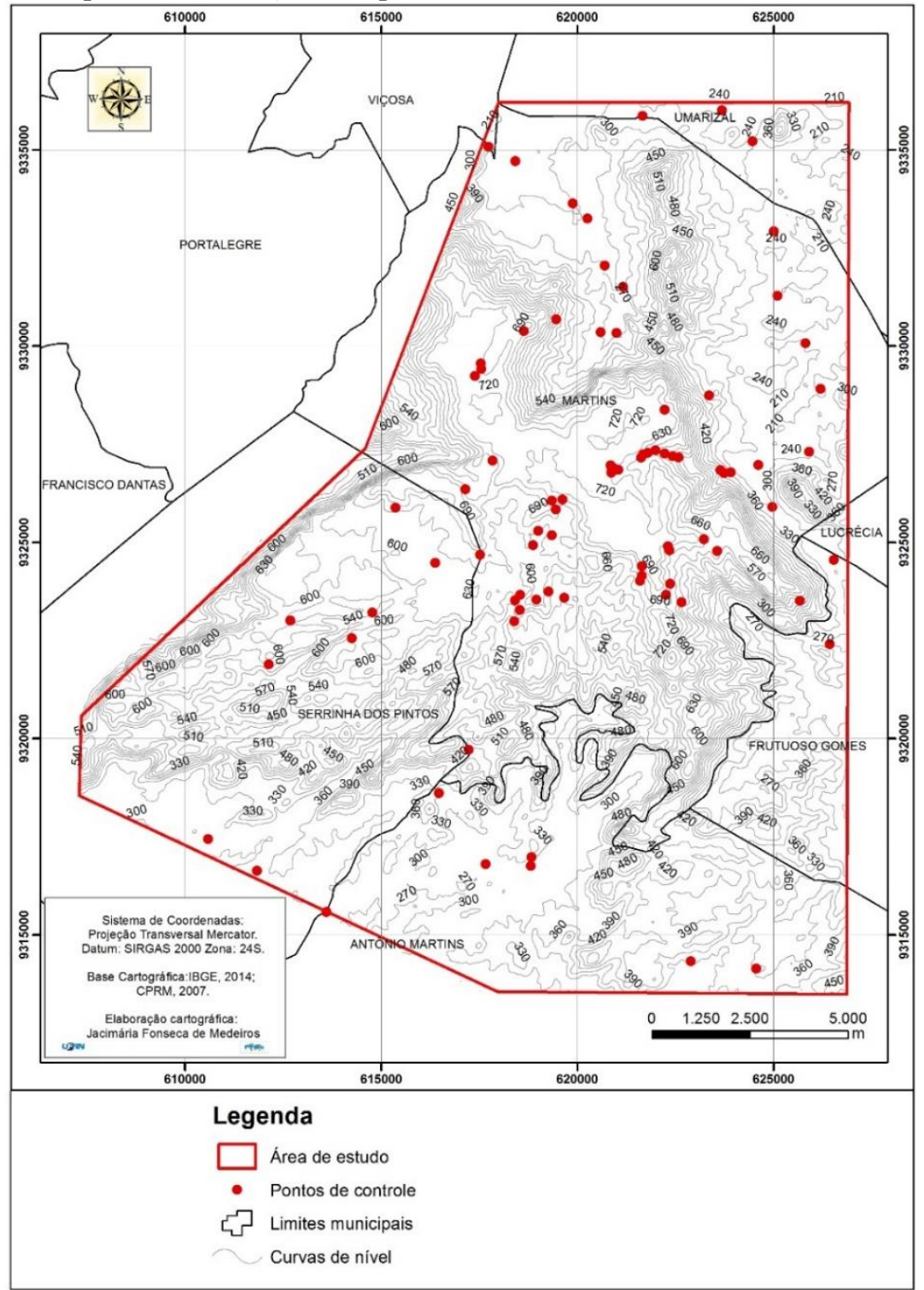

Fonte: elaboração cartográfica de Jacimária F. de Medeiros, jun., 2016.

As variáveis de solos observadas foram a textura (percentagem de areia e percentagem de argila), o pH e a CTC (Capacidade de Troca de Cátions).

As variáveis da cobertura da terra envolveram o porte da formação vegetal: lenhosa alta: $15-7 \mathrm{~m}$, lenhosa média: $7-2 \mathrm{~m}$, lenhosa baixa: $<2$ m e Herbácea, e o uso: extrativismo, pecuária, agricultura e sem uso aparente.

Nesse sentido, as variáveis da pesquisa totalizaram 46 e podem ser evidenciadas na Tabela 1.

\section{Organização e processamento dos dados}

Os dados foram organizados em uma tabela, onde as colunas acomodaram as variáveis e as linhas as parcelas amostradas. A partir da tabela, foram realizados os procedimentos estatísticos, visando a aplicação da técnica de análise multivariada de agrupamento. A análise de agrupamento é definida como um procedimento utilizado para dividir um conjunto de dados em subconjuntos relativamente homogêneos, com base na distância ou similaridade entre os dados (SANTOS, 2004). 
Tabela 1. Variáveis utilizadas para a Compartimentação Geoambiental

\begin{tabular}{|c|c|}
\hline Número & Variáveis \\
\hline \multicolumn{2}{|l|}{ LITOLOGIA } \\
\hline 01 & Rochas Cristalinas \\
\hline 02 & Rochas Sedimentares \\
\hline 03 & Afloramentos \\
\hline 04 & Colúvio \\
\hline \multicolumn{2}{|l|}{ RELEVO } \\
\hline 05 & Topo \\
\hline 06 & Encosta Superior \\
\hline 07 & Meia Encosta \\
\hline 08 & Encosta Inferior \\
\hline 09 & Base \\
\hline 10 & Canal \\
\hline 11 & Escarpado \\
\hline 12 & Muito Íngreme \\
\hline 13 & Íngreme \\
\hline 14 & Inclinado \\
\hline 15 & Suave \\
\hline 16 & Plano \\
\hline 17 & Altitude $>690$ metros \\
\hline 18 & $\begin{array}{l}\text { Atitude entre } 690 \text { e } 450 \\
\text { metros }\end{array}$ \\
\hline 19 & Altitude $<450$ metros \\
\hline 20 & Retilíneo \\
\hline 21 & Convexo \\
\hline 22 & Côncavo \\
\hline \multicolumn{2}{|l|}{ SOLO } \\
\hline 23 & $\mathrm{pH} 4,5$ a 5,2 \\
\hline 24 & pH 5,21 a 6,0 \\
\hline 25 & $\mathrm{pH} 6,01$ a 6,8 \\
\hline 26 & $\mathrm{pH} 6,81$ a 7,7 \\
\hline 27 & CTC 4,82 a 13,69 \\
\hline 28 & CTC 13,7 a 22,57 \\
\hline 29 & CTC 22,58 a 31,45 \\
\hline 30 & CTC 31,46 a 40,33 \\
\hline 31 & Areia 427 a 519 \\
\hline 32 & Areia 519,01 a 612 \\
\hline 33 & Areia 612,01 a 705 \\
\hline 34 & Areia 705,01 a 795 \\
\hline 35 & Argila 40 a 100 \\
\hline 36 & Argila 100,01 a 161 \\
\hline 37 & Argila 161,01 a 222 \\
\hline 38 & Argila 222,01 a 280 \\
\hline $\begin{array}{l}\text { COBERTURA } \\
\text { TERRA }\end{array}$ & \\
\hline 39 & Vegetação herbácea \\
\hline 40 & Vegetação lenhosa baixa \\
\hline 41 & Vegetação lenhosa média \\
\hline 42 & Vegetação lenhosa alta \\
\hline 43 & Sem uso aparente \\
\hline 44 & Extrativismo vegetal \\
\hline 45 & Pecuária \\
\hline 46 & Agricultura \\
\hline
\end{tabular}

Fonte: organizada por Jacimária F. de Medeiros e Luiz A. Cestaro, 2016.
O conjunto de dados, com todas as observações e variáveis obtidas em campo, foi representado na forma de matriz, construída em planilha eletrônica. Nesta etapa, optou-se por analisar/avaliar o comportamento do conjunto das variáveis previamente selecionadas, apoiando-se na técnica estatística Análise de Componentes Principais (PCA), visando avaliar o conjunto das variáveis originais. Uma PCA consiste em análise estatística que pode ser usada para avaliar as inter-relações entre um grande número de variáveis, de modo a condensar a informação em um conjunto menor de variáveis estatísticas, com perda mínima de informação. A utilização dessa técnica visa minimizar as redundâncias que possam existir, possibilitando a captação da maior variabilidade dos dados em poucos componentes, tornando mais simples o mapeamento das informações (ALENCAR, 2009).

Os componentes principais foram obtidos pela solução do sistema:

$\operatorname{det}(R-? l I) a=0$

Sendo: $\mathrm{R}=$ matriz de correlação entre as médias estimadas; ? l = raízes características (ou autovalores) de $\mathrm{R}$; $\mathrm{I}=$ matriz-identidade de dimensão p x p; e a = vetor característico (ou autovetor) associado aos autovalores (HOFFMANN, 1999).

Dessa forma, os autovalores de $\mathrm{R}$ correspondem às variâncias de cada componente e os autovetores normalizados, aos coeficientes de ponderação dos caracteres padronizados.

A PCA foi processada no software PAST Palaeontological Statistics, versão 1.81 (HAMMER et al., 2008).

Depois da determinação dos componentes principais da pesquisa, iniciou-se a fase de escolhas e testes dos métodos de agrupamentos, percebendo-se que os métodos aglomerativos hierárquicos partem do conjunto de todos os elementos separados e, a cada etapa, reúnem os subconjuntos "mais próximos" para construir um novo subconjunto, até a obtenção do conjunto total de indivíduos (ROGERSON, 2012). Hair et al. (2005) destacam que as características de cada variável são combinadas em uma medida de semelhança, que pode ser de similaridade ou dissimilaridade, calculada para todos os pares de variáveis, possibilitando a comparação de qualquer variável com outra pela medida de similaridade e a associação das variáveis semelhantes por meio da análise de agrupamento. As medidas de distância representam a similaridade, que é representada pela proximidade entre as observações ao longo 
das variáveis. Nesse caso, utilizou-se como medida de similaridade, o coeficiente de correlação.

Dentre os métodos aglomerativos hierárquicos, optou-se pelo método de variância mínima de WARD, o qual,

“pressupõe que um grupo será reunido a um outro se essa reunião proporcionar o menor aumento de variância intragrupo. Essa variância será calculada para todas as alternativas de aglomeração, escolhendo a que proporciona a menor variância. $\mathrm{O}$ mesmo procedimento é aplicado a todos os passos da análise. É altamente eficiente na formação de grupos, pois se fundamenta na noção de variância intergrupo.”(SANTOS, 2004)

A Análise de Agrupamento foi processada por meio do software PAST - Palaeontological Statistics, versão 1.81 (HAMMER et al., 2008). Após inserir a matriz de dados no programa, segue-se os seguintes comandos: Multivar Cluster Analysis. $\mathrm{Na}$ sequência, na seção Algorithm, escolhe-se Ward's Method.

O agrupamento das variáveis propiciou a separação de grupos com características homogêneas, denominadas de geofácies. Para fins de espacialização, foi gerado o mapa das geofácies presentes na área de estudo.

\section{Espacialização das unidades geoambientais}

A etapa preliminar à elaboração do mapa envolveu a aquisição da imagem SRTM, baixada diretamente do endereço eletrônico da TOPODATA1 - Banco de Dados Geomorfométricos do Brasil, onde os dados estão organizados em quadrículas, ajustados com a escala de 1:250.000, em formato GeoTiff. O produto original está georreferenciado no datum WGS84, porém os dados SRTM foram convertidos para as coordenadas projetadas (Universal Transverso de Mercator), SIRGAS 2000 UTM, Zone 24S, considerando a maior facilidade de entendimento da localização e melhor qualidade do processamento da grade triangular (TIN).

Para elaboração do mapa das geofácies da Serra de Martins, foi utilizada uma imagem de radar SRTM (SB-24-Z-A- Folha Souza). Utilizando um software de geoprocessamento, especificamente o ArcGIS 10 (software licenciado pelo Núcleo de Estudos Geoambientais e Cartográficos/ Departamento de Geografia/ Universidade do Estado do Rio Grande do Norte/Campus Avançado de Pau dos Ferros) inseriu-se os shapes da delimitação da área de estudo, das curvas de nível e principalmente dos pontos correspondentes a cada agrupamento. A partir daí foram gerados os polígonos para cada grupo, através da técnica de vetorização. O mapa foi produzido em escala 1:2.500.

\section{RESULTADOS E DISCUSSÃO}

\section{Tratamento estatistico dos dados}

O elevado número de variáveis levantadas e a grande massa de dados, muitos deles com pouca variação para influenciar na formação dos grupos, exigiu a redução da dimensionalidade dos dados, proporcionada pelas técnicas de Análise de Componentes Principais, cujos resultados são apresentados na Tabela 2 .

Ao analisar a variação dos dados para cada variável, salienta-se que, as quatro variáveis iniciais, relacionadas a litologia, foram as que apresentaram maior autovalor, com proporção acumulada de variância de 57\%. Percebe-se ainda, que as 35 primeiras variáveis explicaram $100 \%$ da variância, indicando que as 11 restantes são combinações lineares das 35 primeiras.

Assim, assumiu-se que as variáveis relacionadas a litologia, formas de relevo e solos apresentaram 100\% da variância, ou seja, são as mais representativas para diferenciar as unidades geoambientais individualizadas, o que não descarta a importância nessa análise das variáveis relacionadas à cobertura da terra, tendo em vista, combinar-se linearmente com as demais.

\section{Unidades Geoambientais identificadas}

A PCA possibilitou o entendimento de que a base de dados poderia ser truncada em um número de variáveis menor que 46, no entanto, optou-se pelo uso de todas para a aplicação da análise aglomerativa hierárquica de agrupamentos, denominada método de variância mínima de WARD. Salienta-se que esta decisão parte do princípio de que na análise sistêmica todos os elementos constituintes precisam ser considerados. 
Tabela 2. Análise PCA das 46 variáveis.

\begin{tabular}{|c|c|c|c|}
\hline $\begin{array}{c}\text { Componentes } \\
\text { principais } \\
\text { (variáveis) }\end{array}$ & Autovalor & $\begin{array}{l}\text { Variância } \\
\text { (\%) }\end{array}$ & $\begin{array}{c}\text { Proporção } \\
\text { Acumulada } \\
\text { de } \\
\text { Variância } \\
(\%) \\
\end{array}$ \\
\hline 1 & 1,44 & 22,46 & 22,46 \\
\hline 2 & 1,00 & 15,70 & 38,16 \\
\hline 3 & 0,65 & 10,18 & 48,34 \\
\hline 4 & 0,54 & 8,56 & 56,90 \\
\hline 5 & 0,39 & 6,22 & 63,12 \\
\hline 6 & 0,34 & 5,33 & 68,45 \\
\hline 7 & 0,27 & 4,22 & 72,67 \\
\hline 8 & 0,26 & 4,13 & 76,89 \\
\hline 9 & 0,23 & 3,60 & 80,49 \\
\hline 10 & 0,17 & 2,71 & 83,20 \\
\hline 11 & 0,15 & 2,37 & 85,57 \\
\hline 12 & 0,13 & 2,16 & 87,73 \\
\hline 13 & 0,11 & 1,81 & 89,54 \\
\hline 14 & 0,10 & 1,67 & 91,21 \\
\hline 15 & 0,07 & 1,24 & 92,45 \\
\hline 16 & 0,07 & 1,17 & 93,62 \\
\hline 17 & 0,06 & 0,94 & 94,56 \\
\hline 18 & 0,05 & 0,87 & 95,43 \\
\hline 19 & 0,05 & 0,78 & 96,21 \\
\hline 20 & 0,04 & 0,74 & 96,95 \\
\hline 21 & 0,03 & 0,61 & 97,56 \\
\hline 22 & 0,03 & 0,56 & 98,12 \\
\hline 23 & 0,02 & 0,39 & 98,51 \\
\hline 24 & 0,01 & 0,28 & 98,79 \\
\hline 25 & 0,01 & 0,22 & 99,01 \\
\hline 26 & 0,01 & 0,19 & 99,20 \\
\hline 27 & 0,01 & 0,18 & 99,38 \\
\hline 28 & 0,009 & 0,14 & 99,52 \\
\hline 29 & 0,007 & 0,11 & 99,63 \\
\hline 30 & 0,006 & 0,10 & 99,73 \\
\hline 31 & 0,004 & 0,07 & 99,80 \\
\hline 32 & 0,004 & 0,07 & 99,87 \\
\hline 33 & 0,002 & 0,04 & 99,91 \\
\hline 34 & 0,001 & 0,01 & 99,92 \\
\hline 35 & 0,0004 & 0,008 & 100,00 \\
\hline 36 ao 46 & 0,00 & 0,00 & 100,00 \\
\hline
\end{tabular}

Fonte: Jacimária F. de Medeiros e Luiz A. Cestaro, 2016.

O dendrograma gerado permitiu identificar na área de estudo seis agrupamentos, considerados as geofácies presentes na área de estudo (Dendograma 1). Tendo em vista a ausência de teoria que indique em qual altura realizar o corte no dendograma (VICINI, 2005), foi necessário utilizar o conhecimento da área de estudo para apreender que com um corte na linha 9, obter-se-ia seis grupos homogêneos, os quais representam o contexto bem aproximado na área de estudo, quanto as suas geofácies.

O coeficiente de correlação calculado para o dendrograma apresentou o valor 0,6723 , o qual é considerado satisfatório pelo fato de que no uso da medida de similaridade, quanto maior for o valor observado, mais homogêneos serão os grupos (HAIR et al., 2005), evidenciando, assim, consistência no agrupamento.

Assim, a partir da análise aglomerativa hierárquica de agrupamentos foi possível identificar na área, seis grupos, que a partir do sistema taxonômico escolhido (SOTCHAVA, 1978), foram denominados de Classes de Fácie, a saber:

$\checkmark \quad$ Classe de Fácie 1: Superfícies Rebaixadas de Relevo Plano a Suave Ondulado em Embasamento Cristalino com Savana-Estépica Arborizada sobre Luvissolos. Delimitada a partir do agrupamento dos pontos de controle 2, 58, 59, 60, 61, 83, 94, 95, 96, 97, 98 e 99, situados na porção Sul-Sudoeste da área de estudo. Apresenta extensão territorial de $28,60 \mathrm{Km}^{2}$, que representa $9 \%$ da área estudada.

$\checkmark \quad$ Classe de Fácie 2: Superfícies Rebaixadas de Relevo Dissecado em Embasamento Cristalino com Savana-Estépica Arborizada sobre Argissolos Vermelho-Amarelos Eutróficos. Esta Classe de Fácie foi formada a partir do agrupamento dos pontos de controle $3,14,15,16$, $45,46,47,48,72,73,74,75,76,77,78,79,80,81$, $82,85,86,87,91,92$ e 93 , localizados nas porções Sul, Sudeste, Leste, Nordeste e Norte da área de estudo, estendendo-se por $71,68 \mathrm{~km}^{2}$, que representa $23 \%$ da área amostrada.

$\checkmark \quad$ Classe de Fácie 3: Escarpas Serranas de Relevo Dissecado em Embasamento Cristalino com Savana-Estépica Florestada sobre Neossolos Litólicos. Definida pelo agrupamento dos pontos de controle $6,27,34,35,62,63,64,67,68,84$, 103, 104, 105, distribuídos nas porções Norte, Sul, Leste e Oeste, com uma extensão de 122 $\mathrm{Km}^{2}$, que corresponde a aproximadamente $40 \%$ da área de estudo, sendo, portanto, a Classe de Fácie de maior abrangência.

$\checkmark \quad$ Classe de Fácie 4: Superfícies Tabulares com Relevo Plano em Embasamento Sedimentar com Floresta Estacional Semidecidual sobre Latossolos Amarelos Distróficos. Formou-se a partir do agrupamento dos pontos de controle 7 , $8,19,20,21,22,23,24,25,26,28,29,30,31,43$, 50, 51 e 65 situados na porção central da área de estudo . Abrange uma área de $16 \mathrm{Km}^{2}$, equivalente a $5 \%$ do total.

$\checkmark \quad$ Classe de Fácie 5: Escarpas Serranas com Relevo Suave Ondulado em Embasamento Cristalino com Savana-Estépica Florestada sobre Luvissolos. Definida pelo agrupamento dos seguintes pontos de controle: $36,37,38,39,40$, $41,57,69,70,88,89,90,100,101$ e 102, localizados na porção central, ocupando uma área de $49 \mathrm{Km}^{2}$, ou seja, $16 \%$ da área de estudo. 
Classe de Fácie 6: Escarpas Erosivas de Relevo Dissecado em Embasamento Cristalino e Capeamento Sedimentar com Savana Estépica Florestada sobre Neossolos Litólicos. Esta Classe de Fácie foi definida pelo agrupamento dos pontos de controle $1,4,5,9,10,11,12,13,17,18$,
$32,33,42,44,49,52,53,54,55,56,66$ е 71 , ocupando uma área de $25 \mathrm{~km}^{2}$, que corresponde a $8 \%$ do universo amostral. Situa-se na porção central da área de estudo, bordejando a Classe de Fácie 4.

Dendograma 1. Formação de seis grupos, considerados as geofácies identificadas na área de estudo.

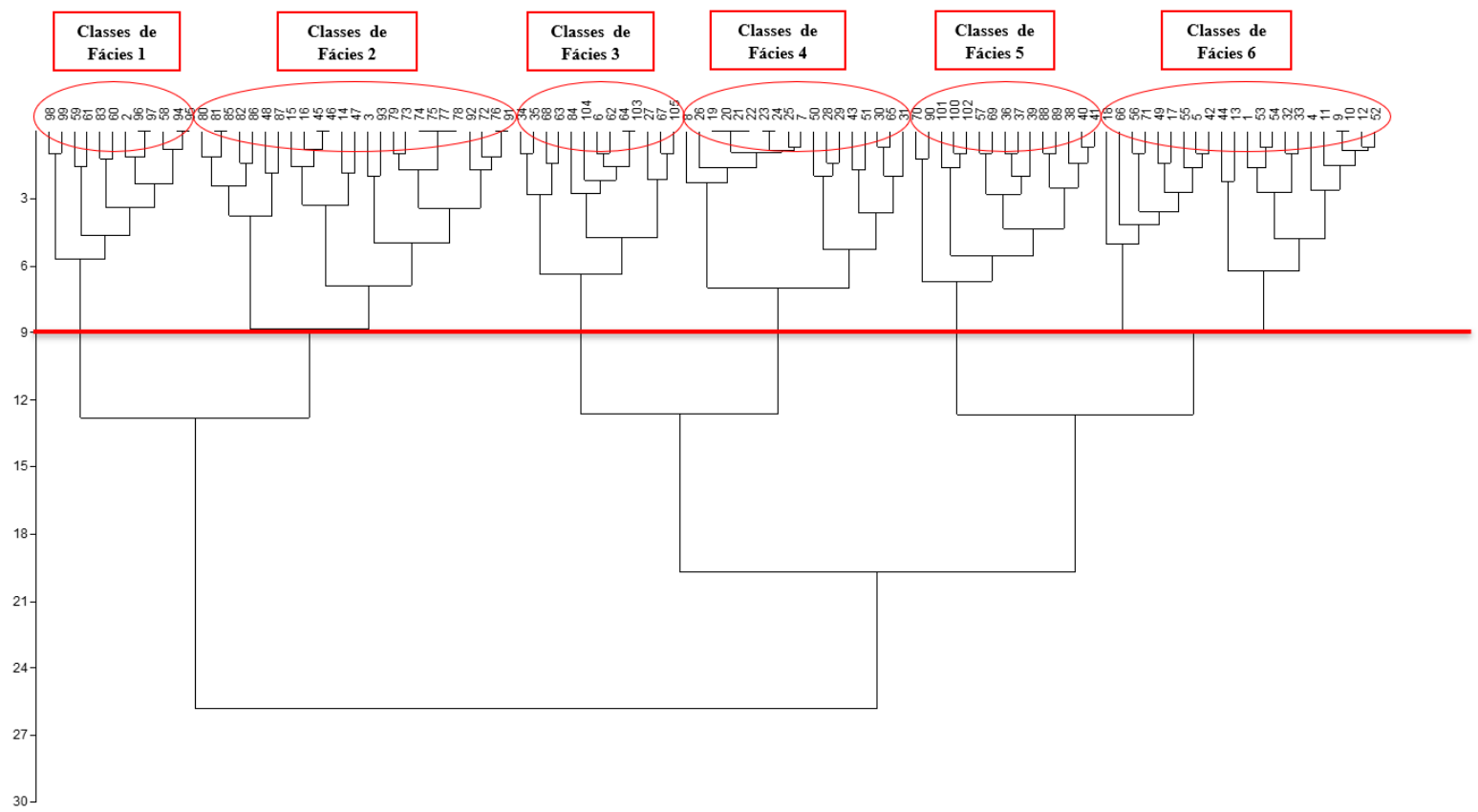

Fonte: organizada por Jacimária F. de Medeiros e Luiz A. Cestaro, 2016.

A diversidade de unidades encontrada na área de estudo era esperada em função de tratarsea serra de um encrave, sob os diversos aspectos naturais e de uso, num ambiente relativamente mais homogêneo em que se constitui a Depressão Sertaneja dominante regionalmente.

As principais características geoambientais (litologia, forma de relevo, características pedológicas e cobertura da terra) das Classes de Fácies acima descritas, encontram-se dispostas de forma sintética no quadro 1 . A cartografia das Classes de Fácies da área de estudo pode ser visualizada no Mapa 3.

Quadro 1. Características das Classes de Fácies na área de estudo.

\begin{tabular}{|c|c|c|c|c|c|}
\hline Fácie & Rochas & Relevo & Solos & Vegetação & Uso \\
\hline $\begin{array}{l}\text { Classes de } \\
\text { Fácies } 1\end{array}$ & $\begin{array}{c}\text { Rochas } \\
\text { Cristalinas }\end{array}$ & $\begin{array}{l}\text { Formas } \\
\text { Côncavas }\end{array}$ & Luvissolos & $\begin{array}{l}\text { Savana-Estépica } \\
\text { Arborizada }\end{array}$ & $\begin{array}{l}\text { Culturas temporárias e } \\
\text { permanentes; Pecuária }\end{array}$ \\
\hline $\begin{array}{l}\text { Classes de } \\
\text { Fácies } 2\end{array}$ & $\begin{array}{c}\text { Rochas } \\
\text { Cristalinas }\end{array}$ & $\begin{array}{c}\text { Formas } \\
\text { Retilíneas }\end{array}$ & $\begin{array}{c}\text { Argissolos } \\
\text { Vermelho-Amarelo } \\
\text { Eutrófico. }\end{array}$ & $\begin{array}{l}\text { Savana-Estépica } \\
\text { Arborizada }\end{array}$ & $\begin{array}{l}\text { Culturas temporárias e } \\
\text { permanentes; Pecuária }\end{array}$ \\
\hline $\begin{array}{l}\text { Classes de } \\
\text { Fácies } 3 \\
\end{array}$ & $\begin{array}{c}\text { Rochas } \\
\text { Cristalinas } \\
\end{array}$ & $\begin{array}{c}\text { Formas } \\
\text { Convexas }\end{array}$ & Neossolos Litólicos & $\begin{array}{c}\text { Savana-Estépica } \\
\text { Florestada }\end{array}$ & $\begin{array}{l}\text { Culturas temporárias e } \\
\text { permanentes (incipiente) }\end{array}$ \\
\hline $\begin{array}{l}\text { Classes de } \\
\text { Fácies } 4\end{array}$ & $\begin{array}{c}\text { Rochas } \\
\text { Sedimentares }\end{array}$ & $\begin{array}{l}\text { Formas } \\
\text { Tabulares }\end{array}$ & $\begin{array}{l}\text { Latossolos } \\
\text { Amarelos } \\
\text { Distróficos }\end{array}$ & $\begin{array}{l}\text { Floresta Estacional } \\
\text { Semidecidual }\end{array}$ & $\begin{array}{c}\text { Culturas temporárias e } \\
\text { permanentes; núcleo } \\
\text { urbano }\end{array}$ \\
\hline $\begin{array}{l}\text { Classes de } \\
\text { Fácies } 5\end{array}$ & $\begin{array}{c}\text { Rochas } \\
\text { Cristalinas }\end{array}$ & $\begin{array}{c}\text { Formas } \\
\text { Côncavas }\end{array}$ & Luvissolos & $\begin{array}{l}\text { Savana-Estépica } \\
\text { Florestada }\end{array}$ & $\begin{array}{c}\text { Culturas temporárias e } \\
\text { permanentes (incipiente) }\end{array}$ \\
\hline $\begin{array}{l}\text { Classes de } \\
\text { Fácies } 6\end{array}$ & $\begin{array}{c}\text { Rochas } \\
\text { Sedimentares }\end{array}$ & $\begin{array}{l}\text { Escarpas } \\
\text { Erosivas }\end{array}$ & $\begin{array}{l}\text { Neossolos } \\
\text { Litílicos }\end{array}$ & $\begin{array}{l}\text { Savana Estépica } \\
\text { Florestada }\end{array}$ & $\begin{array}{l}\text { Culturas temporárias e } \\
\text { permanentes }\end{array}$ \\
\hline
\end{tabular}

Fonte: organizada por Jacimária F. de Medeiros e Luiz A. Cestaro, 2016. 
Mapa 3. Classes de Fácies da Serra de Martins-RN.

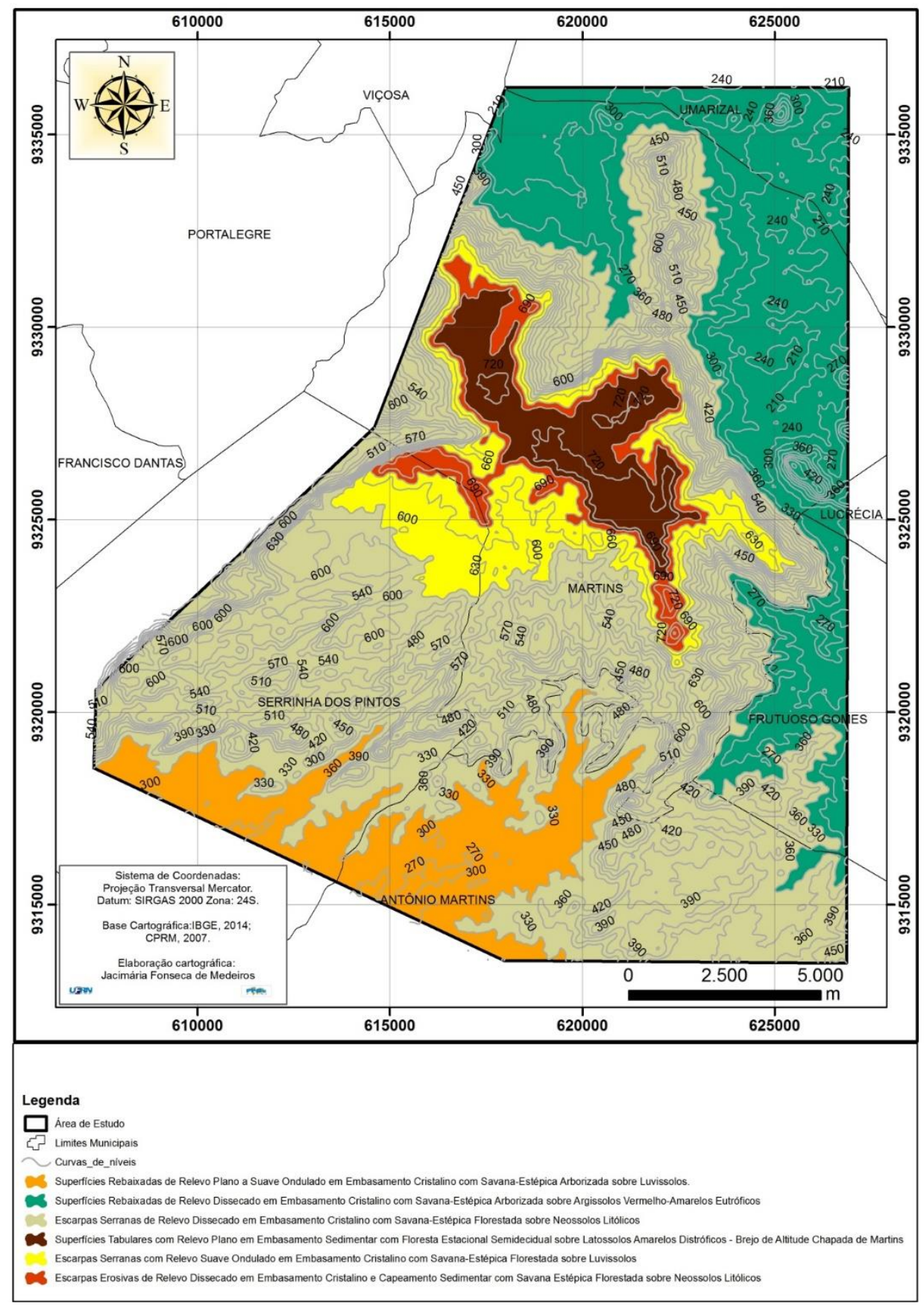

Fonte: elaboração cartográfica de Jacimária F. de Medeiros, jun., 2016.

\section{REFERÊNCIAS}

ALENCAR, B. J. Análise multivariada aplicada ao tratamento da informação espacial: uma abordagem matemáticocomputacional em análise de agrupamentos e análise de componentes principais. Tese (Doutorado em Geografia e Tratamento da Informação Espacial) - Belo Horizonte: PUC. 2009.

BAILEY, R. G. Ecosystem Geography: From Ecoregions to Sites. 2ed. New York: Springer.
2009.

BARROS, J. S.; CASTRO, A. A. J. F. C. Compartimentação geoambiental no Complexo de Campo Maior, PI: uma área de tensão ecológica. Interações, Campo Grande, v. $8, \quad$ n. $13, \quad$ p. $119-130,2006$. https://doi.org/10.1590/S1518. 70122006000200013

BRASIL. Decreto $\mathrm{n}^{\circ} \mathbf{4 . 2 9 7}$, de 10 de julho de 2002. 2002. Disponível em: $<$ http://www.icmbio.gov.br/cepsul/images/stori es/legislacao/Decretos/2002/dec_4297_2002_zo neamentoecologico_economicodobrasil_zee_alt 
rd_dec_7378_2010.pdf>. Acesso: Junho 06, 2015.

BRASIL. Decreto $n^{\circ} \mathbf{5 . 3 0 0}$ de 7 de dezembro de 2004. 2004. Disponível em: <http://www.planalto.gov.br/ccivil_03/_Ato200 4-2006/2004/Decreto/D5300.htm>. Acesso: Junho 25, 2015.

BRASIL. Ministério do Meio Ambiente Secretaria de Políticas para o Desenvolvimento Sustentável - Programa Zoneamento Ecológico-Econômico. Programa ZEE do Território Nacional: diretrizes metodológicas para o Zoneamento EcológicoEconômico do Brasil. 3. ed. Brasília: MMA, 2006.

CARVAlHO, R. G.; MEIRELES, A. J. A. Dinâmica Ambiental como critério para o zoneamento do litoral leste de Fortaleza - CE. Mercator, Fortaleza, v.7, n. 14, p. 166-178, $2008 . \quad$ Disponível em: <http://www.mercator.ufc.br/mercator/article/ view/217>. Acesso: July 07, 2015.

CAVALCANTI. L. C. de S. Da Descrição de Áreas à Teoria dos Geossistemas: Uma Abordagem Epistemológica sobre Sínteses Naturalistas. Tese (Doutorado em Geografia) - Recife: UFPE. 2013.

CAVALCANTI, L. C. S. Geossistemas de Curuçá, Bahia. Clio Arqueológica (RecifeUFPE), v. 32, n 3, p. 61-87. 2017. Disponível em:

$<$ https://www3.ufpe.br/clioarq/images/docume ntos/V32N3-2017/artigo3v32n3.pdf>. Acesso: Julho 07, 2015.

CESTARO, L. A.; ARAÚJO, P. C. MEDEIROS, C. N.; CISNEIROS, R.; ARAÚJO, L. P. Proposta de unidades geoambientais para o Rio Grande do Norte. In: Simpósio Brasileiro de Geografia Física Aplicada - natureza, geotecnologia, ética e gestão do território, 2007, Natal. Anais... Natal: Universidade Federal do Rio Grande do Norte, 2007.

CHRISTOFOLETTI, A. Modelagem de sistemas ambientais. São Paulo: Edgard Blücher, 1999.

CHRISTOFOLETTI, A. Geomorfologia. São Paulo: Edgard Blücher, 1980. 188 p.

HAIR, J. F.; ANDERSON, R. E.; TATHAM, R. L.; BLACK, W. C. Análise multivariada de dados. Porto Alegre: Bookman, 2005.

HAMMER, O.; HARPER, D. A. T.; RYAN, P. D. PAST - Paleontological Statistics, ver. 1.81 (http://folk.uio.no/chammer/past). 2008.

HOFFMANN, R. Componentes principais e análise fatorial. 4. ed. Piracicaba: ESALQ/USP, 1999.

IBGE. Instituto Brasileiro de Geografia e Estatística. Zoneamento Geoambiental do Estado do Maranhão: diretrizes gerais para ordenação territorial. Divisão de Geociências da Bahia, Salvador. 1997.

IBGE. Instituto Brasileiro de Geografia e Estatística. Manual técnico de Geomorfologia. Rio de Janeiro: IBGE. 2 ed. 2009. (Manuais Técnicos em Geociências).

ISACHENKO, A. G. Principles of landscape Science and physical-geographic regionalization. Melbourne: Melboune University Press, 1973.

LIMA, F. J.; CESTARO, L. A.; ARAÚJO, P. C. Sistemas geoambientais do municípo do Crato/CE. Mercator, Fortaleza, v. 9, n. 19, p. 129-142. 2010. https://doi.org/10.4215/RM2010.0919.0010.

PHILIPPS, J. D. Earth Surface Systems: Complexity, ordes and scale. Oxford: Blackwell, 1999.

RODRIGUES, J. M. M.; SILVA, E. V.; CAVALCANTI, A. P. B. Geoecologia das Paisagens: uma visão geossistêmica da análise ambiental. 3. ed. Fortaleza: Edições UFC, 2010.

RODRIGUES, J. M. M.; SILVA, E. V. da. Planejamento e Gestão Ambiental: subsídios da geoecologia das paisagens e da teoria geossistêmica. 2. ed. Fortaleza: Edições UFC, 2016.

ROGERSON, P. A. Métodos estatísticos para Geografia: um guia para o estudante. $3^{\mathrm{a}} \mathrm{Ed}$. Porto Alegre: Bookman, 2012.

ROSSETE, A. N.; SANTOS, J. E. Zoneamento Ambiental do Município de Querência (MT). In: SANTOS, J. E.; SILVA, C. J.; MOSCHINI, L. E. (Org.). Paisagem, biodiversidade e cultura. São Carlos: Rima Editora 2012, p. 01-32.

SALES. V. C. Geografia, sistemas e análise ambiental: abordagem crítica. Espaço e Tempo, São Paulo, n. 16, p.125-141, 2004. https://doi.org/10.11606/issn.21790892.geousp.2004.73959.

SANTOS, R. F. Planejamento ambiental: Teoria e prática. São Paulo: Oficina de Textos, 2004. $184 \mathrm{p}$.

SATO, S. E.; CUNHA, C. M. L. Carta de unidades geoambientais do município de Itanhaém, São Paulo, Brasil. Revista da Gestão Costeira Integrada, v. 13, p. 329342, 2013. Disponível em: $<$ http://www.scielo.mec.pt/scielo.php?script=sc i_arttext\&pid=S1646-88722013000300006 $>$. Acesso: July 06, 2015.

SILVA, J. S. V; SANTOS, R. F. Zoneamento para o planejamento ambiental: vantagens e restrições de métodos e técnicas. Cadernos de Ciência \& Tecnologia, Brasília, v. 21, n. 2, p. 221-263, 2004. Disponível em: 
<https://seer.sct.embrapa.br/index.php/cct/arti cle/view/8710>. Acesso: JulHO 14, 2015.

SOTCHAVA, V. B. O estudo de geossistemas. São Paulo, Instituto de Geografia USP: Métodos em Questão, n. 16, p. 51, 1977.

SOTCHAVA, V. B. Introdução à Teoria do Geossistema. Novasibéria: Nauka, 1978.

SOUZA, M. J. N.; CARVALHO, G. M. B. S.; SANTOS, S. M.; OLIVEIRA, V. P. V.; CRUZ, L. B. Compartimentação Geoambiental do Estado do Ceará. Fortaleza: FUNCEME, 2009.

TRICART, J.; KIEWITDEJONGE,

C.

Ecogeography and rural management. Harlowl: Longman Scientific, 1992.

VICINI, L. Análise multivariada da teoria à prática. 2005. 215pf. Monografia (Especialização em Estatística e Modelagem Quantitativa no Departamento de Estatística) - Universidade Federal de Santa Maria, Santa Maria. 2005. 